\title{
Evaluating the usefulness of continuous leaf turgor pressure measurements for the assessment of Persimmon tree water status
}

\author{
M. A. Martínez-Gimeno ${ }^{1}$ M. Castiella ${ }^{2} \cdot$ S. Rüger $^{2} \cdot$ D. S. Intrigliolo ${ }^{1,3} \cdot$ C. Ballester ${ }^{3,4}$
}

Received: 14 March 2016 / Accepted: 29 September 2016 / Published online: 4 October 2016

(c) The Author(s) 2016. This article is published with open access at Springerlink.com

\begin{abstract}
Continuous plant water status monitoring is crucial in order to improve irrigation management. The noninvasive Yara ZIM-probe was assessed for detecting plant water stress in Persimmon trees (Diospyros kaki L.f.). The probe measures the pressure transfer function $\left(P_{\mathrm{p}}\right)$ through a patch of an intact leaf, which is inversely correlated with the turgor pressure. This technology was evaluated in two parallel experiments involving either distinct watering regimes or rootstocks with different drought tolerance [Diospyros lotus (L) and Diospyros virginiana (V)]. Concomitant measurements of midday stem water potential $\left(\Psi_{\text {stem }}\right)$ and trunk diameter variations were taken throughout the experiments. $P_{\mathrm{p}}$ was highly correlated with $\Psi_{\text {stem }}$. Persimmon leaves exhibited the inversed $P_{\mathrm{p}}$ curve phenomena under water stress, which enabled the association of a particular range of $\Psi_{\text {stem }}$ to each of the three leaf turgor states defined. Persimmon trees with no sign of initial or total inversion ensured $\Psi_{\text {stem }}$ above $-0.8 \mathrm{MPa}$, values considered of a well-watered Persimmon tree. Yara ZIMprobe readings as well as $\Psi_{\text {stem }}$ and trunk diameter variation measurements pointed $\mathrm{L}$ as a more sensitive rootstock to
\end{abstract}

Communicated by E. Fereres.

M. A. Martínez-Gimeno

magimeno@cebas.csic.es

1 Center for Applied Biology and Soil Sciences (CEBAS), Murcia, Spain

2 YARA ZIM Plant Technology GmbH, Hennigsdorf, Germany

3 Valencian Institute for Agricultural Research (IVIA), Valencia, Spain

4 Present Address: Centre for Regional and Rural Futures (CeRRF), Deakin University, Griffith, NSW, Australia drought than V. In conclusion, results showed that the Yara ZIM-probe can be used to continuously monitor water status in Persimmon trees although further research would be needed to ensure their feasibility for scheduling irrigation.

\section{Introduction}

Water is becoming a limiting factor for crop production in much of the world (IPCC 2014). That is the case of the Mediterranean ecosystems where the scarce rainfall is not enough to cover the high crop water requirements during most of the season, and the water resources available are limited. Optimizing irrigation must be then a priority in order to ensure the sustainability of the agricultural systems.

Water-saving irrigation strategies such as the partial rootzone drying or regulated deficit irrigation (RDI) have been studied in depth in experimental and commercial orchards with successful results (Ruiz-Sanchez et al. 2010). A common conclusion in all the studies related to the implementation of water-saving irrigation strategies is that water stress monitoring is crucial in order to avoid an undesirable impact on yield. A series of plant-based water stress indicators can be found in the market to continuously monitor the plant water status throughout the season. Stem dendrometers, porometers, sap flow probes or the measurement of canopy temperature among others have been studied during the last decades in woody crops to automatically monitor the plant water status in an attempt to substitute the stem water potential measurement, which is the accepted method as reference despite being a destructive and timeand labor-consuming technique (Ballester et al. 2013a; Fernández and Cuevas 2010; Fernández 2014; Jones et al. 2009; Ortuño et al. 2010). The use of these methods in the 
field, however, is still a constraint for growers due to different reasons such as difficulty of installation, maintenance requirements and the need of processing a large amount of data (Fernández 2014).

Monitoring the leaf turgor pressure with a highly sensitive pressure sensor clamped to a patch of a leaf (Yara ZIM-probe, Zimmermann et al. 2008) has been reported as an easier to install and easier to use technique than the above-mentioned methods with a great potential to be used at field by growers (Fernández 2014).

The noninvasive Yara ZIM-probe is a magnetic-based probe that measures the pressure $\left(P_{\mathrm{p}}\right)$ transfer function through a patch of an intact leaf. This $P_{\mathrm{p}}$ has been shown to be inversely correlated with the turgor pressure (Zimmermann et al. 2008, 2009; Westhoff et al. 2009). The usefulness of the Yara ZIM-probe to detect plant water stress has been studied on several horticultural and fruit crops, providing evidence that it can detect changes in turgor pressure caused by variations in the microclimate or in the soil water availability (Westhoff et al. 2008; Zimmermman et al. 2009; Rüger et al. 2010, 2011; Ehrenberger et al. 2012; Fernández et al. 2011; Rodriguez-Dominguez et al. 2012). Moreover, some studies suggest that its use has the potential for efficiently select genotypes tolerant to water stress environments (Kant et al. 2014). Different approaches such as the assessment of the daily or nightly maximum $P_{\mathrm{p}}$ value, the turgor recovery phase during the afternoon or the reverse of the $P_{\mathrm{p}}$ curve, however, must be followed to determine the degree of stress reached by the plants depending on their physiological characteristics and their tolerance or sensitivity to drought stress, which makes necessary the assessment of this technology for each particular case.

Persimmon (Diospyros kaki L.f.) cultivation in Spain has steadily increased in the last decades from a cropped area of 2.000 ha in 2002, to an approximately 13.000 ha in 2014 (Perucho 2015). This notable increase in production is mainly due to the current replacement of citrus with Persimmon trees, particularly with the $c v$. 'Rojo Brillante,' which fruit reaches a higher value in the market than oranges, thanks to a postharvest treatment with high $\mathrm{CO}_{2}$ concentrations that removes its astringency (Arnal and Río 2003). Studies performed in Valencia, Spain, with the $c v$. 'Rojo Brillante' showed that RDI strategies may lead growers to obtain water savings of $20 \%$ without any reduction in yield, increasing then the water use efficiency (Buesa et al. 2013). Results also showed that fruit weight reduction in RDI trees caused a decrease in the fruit commercial value, pointing out that further research would be needed to define a successful RDI strategy for this crop. The Yara ZIM-probe technology could be a suitable tool to be used in this crop for irrigation scheduling in order to properly manage water stress and avoid any fruit size reduction that could affect the economic return obtained by farmers.
The objectives of the present study were: (1) to assess the feasibility of the Yara ZIM-probe for detecting plant water stress in Persimmon trees; (2) to explore the relationships between $P_{\mathrm{p}}$ and $\Psi_{\text {stem }}$ for their possible use as a tool for irrigation scheduling in this crop; and (3) finally, to test the sensitivity of the Yara ZIM-probe in two rootstocks of differing drought tolerance.

\section{Materials and methods}

\section{Plot and irrigation treatments}

The experiment was performed during 2014 in a commercial orchard planted with Persimmon trees $c v$. 'Rojo Brillante' grafted onto two contrasting rootstocks in vigor, Diospyros lotus (L) and Diospyros virginiana (V) at a spacing of $5 \mathrm{~m} \times 2.5 \mathrm{~m}$. The plot was located in Liria $\left(40^{\circ} \mathrm{N}\right.$, elevation $\left.300 \mathrm{~m}\right)$, Valencia, Spain, where the climate is typically Mediterranean and the soil is sandy loam with $32 \%$ by weight stones and an effective depth of $0.8 \mathrm{~m}$. Soil density ranged from 1.35 to $1.45 \mathrm{t} \mathrm{m}^{-3}$ and was considered of low fertility ( 0.66 organic matter and $0.05 \%$ total $\mathrm{N}$ ).

Irrigation was applied with two drip lines leaving ten pressure compensated emitters $\left(4 \mathrm{~L} \mathrm{~h}^{-1}\right)$ per tree. Water had an average electrical conductivity (EC) of $1.1 \mathrm{dS} \mathrm{m}^{-1}$ and an average $\mathrm{Cl}$ concentration of $122 \mathrm{mg} \mathrm{L}^{-1}$. Irrigation was applied according to the estimated crop evapotranspiration $\left(\mathrm{ET}_{\mathrm{c}}=\mathrm{ET}_{\mathrm{o}} \times K_{\mathrm{c}}\right)$. Reference evapotranspiration, $\mathrm{ET}_{\mathrm{o}}$, (Allen et al. 1998) was obtained from a weather station located near the orchard, which also measured the solar radiation (Pyranometer CMP3, Kipp \& Zonen, Delft, The Netherlands). Crop coefficient applied ranged from 0.2 in March to 0.9 at full canopy growth. As a part of an outgoing experiment, trees had been irrigated at 100 and $125 \% \mathrm{ET}_{\mathrm{c}}$.

The Yara ZIM-probes were tested on trees grafted on both rootstocks and irrigated at both rates. In a first experiment, trees grafted onto $\mathrm{L}$ and irrigated at $100 \%$ $\mathrm{ET}_{\mathrm{c}}$ (L-WW) during the whole experiment (total amount applied $332.5 \mathrm{~mm}$ ) were compared with trees grafted onto the same rootstock (L-DS) in which irrigation was withheld during two periods from August 18th to August 23rd [day of the year (DOY) 230-235] and from August 29th to September 3rd (DOY 241-246). L-DS trees were irrigated as L-WW trees between the two drought cycles. A second experiment was then set up with trees irrigated at $125 \%$ $\mathrm{ET}_{\mathrm{c}}$ (total amount received $366.6 \mathrm{~mm}$ ) in order to compare the behavior of trees grafted onto L (L-125-DS) and $\mathrm{V}$ (V-125-DS) rootstocks when subjected to drought cycles. In these trees, irrigation was withheld from August 25th to September 3rd (DOY 237-246). 
The orchard was divided into three blocks of three rows each where the treatments were applied. All the treatments consisted of 21 trees (seven trees per row) with the five trees of the mid-row (perimeter trees were avoid) used for the measurements. The L-125-DS and V-125-DS treatments, in which four trees were used for the plant water status measurements, were carried out in the block of the middle while the L-WW and L-DS treatments in the remainder blocks.

\section{Leaf turgor monitoring}

The basic principle of the Yara ZIM-probe is described by Zimmermann et al. (2008) and the principle of the magnetic leaf patch clamp pressure probe by Westhoff et al. (2009). Briefly, the Yara ZIM-probe consists of two magnets that exert an external pressure to a patch of a leaf covering an area of $87 \mathrm{~mm}^{2}$. One of the magnets contains a highly sensitive pressure sensor able to detect pressure variations up to $300 \mathrm{kPa}$. The sensor measures the difference in pressure between the magnets and the leaf turgor, named patch pressure $\left(P_{\mathrm{p}}\right)$, and therefore provides information about relative changes in leaf turgor at real time. The distance between the magnets can be regulated in order to set up the most suitable initial $P_{\mathrm{p}}$, which ranges between 10 and $60 \mathrm{kPa}$.

All the Yara ZIM-probes were previously tested under laboratory conditions to ensure that ambient temperature $\left(T_{\mathrm{a}}\right)$ did not have any influence on their readings.

Selected trees from each treatment were equipped with two Yara ZIM-probes each (8-10 Yara ZIM-probes/treatment) on 13th and 14th of May, 2014. The Yara ZIMprobes were installed in mature leaves located in the east side of the canopies. In order to distinguish between relative changes in leaf turgor caused by water stress and those caused by microclimate variations (Zimmermann et al. 2013a), relative humidity $(\mathrm{RH})$ and $T_{\mathrm{a}}$ sensors (Yara ZIM Plant Technology GmbH (Hennigsdorf, Germany) were also installed in the orchard. All probes (leaf turgor, $T_{\mathrm{a}}$ and $\mathrm{RH}$ ) were connected by cable to transmitters which sent the data wirelessly every 5 min over a distance of up to $1500 \mathrm{~m}$ to a central controller (Yara ZIM Plant Technology GmbH Hennigsdorf, Germany). The controller contains a GPRS modem which is linked to an Internet server where data are stored and available for real-time inspection and download.

\section{Other plant water status determinations}

Measurements of $\Psi_{\text {stem }}$ were carried out during the experiment to determine the plant water status in all the trees equipped with the Yara ZIM-probes. Measurements were performed at solar noon with a Scholander pressure chamber (PMS Instrument Company, mod. 600, OR, USA) using 2-4 mature leaves per tree previously bagged with aluminum foil for at least $1 \mathrm{~h}$ before the measurements to avoid transpiration (Turner 1981).

The four selected trees from L-125-DS and V-125-DS treatments (grafted onto the two contrasting rootstocks) were equipped with linear variable differential transformers (LVDT, Schlumberger mod. DF-2.5) to monitor trunk diameter variations during the drought stress cycles. Each sensor was fixed to the main trunk of the tree by a metal frame of Invar (a metal alloy with a minimal thermal expansion), located about $25 \mathrm{~cm}$ from the ground. All the transformers were previously calibrated in the laboratory by means of a precision micrometer (Verdtech SA, Spain). The trunk diameter variations were used to calculate the maximum daily trunk shrinkage (MDS) by obtaining the difference between the maximum (MXTD) and minimum (MNTD) diameter in a day. At the beginning of the experiment, trees grafted onto $\mathrm{L}$ and $\mathrm{V}$ had, respectively, an average trunk perimeter of $0.25 \pm 0.004$ and $0.23 \pm 0.020 \mathrm{~m}$. Data were automatically recorded every $30 \mathrm{~s}$ using a data logger (model CR10X) connected to an AM16/32 multiplexer programmed to report mean values every $30 \mathrm{~min}$.

\section{Data analysis}

Data were analyzed using Statgraphics X64, Origin 2015 (Microcal Software Inc., Northampton, MA) and SigmaPlot 11.0. The relationship between $P_{\mathrm{p}}$ and the others water status indicators used during the measurement was explored by ANOVA and the least significant difference (LSD) procedure. Both methods take into account that values of $P<0.05$ are considered to be statistically significant. Data shown are mean \pm standard deviation.

\section{Results}

\section{Meteorological conditions}

Total $\mathrm{ET}_{\mathrm{o}}$ and rainfall registered during the experiment (from April 1st to September 10th) were of 787 and $63 \mathrm{~mm}$, respectively, which can be considered typical values for the area of study. Daily means of $T_{\mathrm{a}}$ ranged from 12.2 to $28.57{ }^{\circ} \mathrm{C}$ with a maximum temperature recorded in August of $40.5^{\circ} \mathrm{C}$. Daily means of $\mathrm{RH}$ ranged from 28.9 to $76.2 \%$ with a minimum value reached in July (9.2\%).

\section{Experiment 1: L-WW versus L-DS}

\section{Stem water potential measurements}

The L-WW treatment in which water restrictions were not applied had $\Psi_{\text {stem }}$ values around $-0.60 \mathrm{MPa}$ during the whole experiment (mean $\Psi_{\text {stem }}$ of $-0.62 \pm 0.01 \mathrm{MPa}$; 


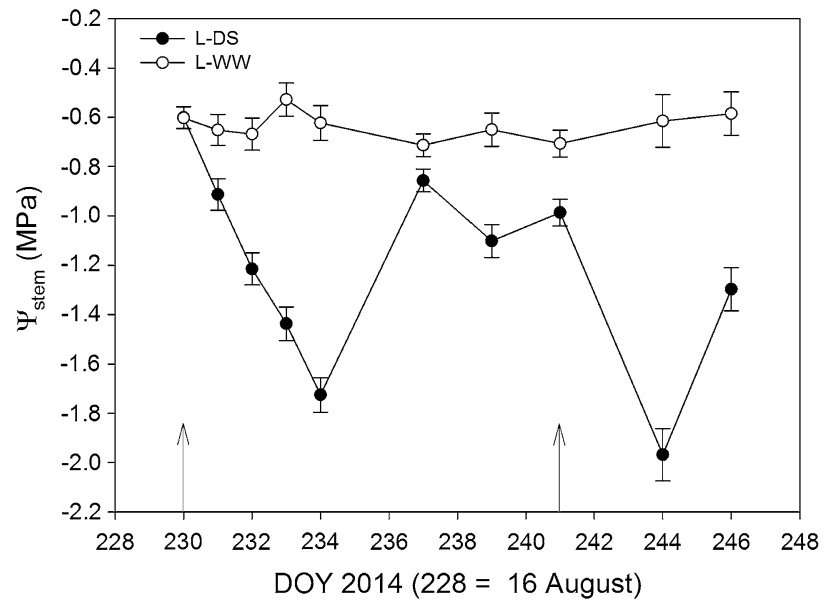

Fig. 1 Stem water potential $\left(\Psi_{\text {stem }}\right)$ evolution in control (L-WW) and non-irrigated trees (L-DS) during the drought cycles. Each point is the average of 10-20 leaves (5 trees per treatment). Vertical bars represent the \pm LSD intervals, and arrows indicate the starting of the drought cycles

Fig. 1). L-DS trees had similar $\Psi_{\text {stem }}$ values to L-WW trees at the beginning of the experiment. Once water restrictions began, $\Psi_{\text {stem }}$ dropped steadily to a minimum value of -1.73 and $-1.93 \mathrm{MPa}$ during the first and second drought cycles, respectively (Fig. 1).

\section{Leaf turgor monitoring with the Yara ZIM-probes}

A daily continuous increase in maximum (recorded at midday) and minimum (recorded at night) $P_{\mathrm{p}}$ was observed in all of the Yara ZIM-probe sensors at the beginning of the experiment just after clamping. Some probes showed a steadily $P_{\mathrm{p}}$ increase similar to the increase in air temperature recorded in May and stabilized after a couple of weeks. Other probes (about $35 \%$ ), however, exhibited a sharp increase in $P_{\mathrm{p}}$ reaching the maximum values detected by the sensor (250-300 kPa) in weeks (Fig. 2). These probes were reclamped again (several times in some occasions) until the $P_{\mathrm{p}}$ readings were more stable and treatments began (end of June).

Three different daily $P_{\mathrm{p}}$ curve shapes were obtained depending on the range of stress reached by the trees. Each of these shapes was associated to a leaf turgor state as reported in Ehrenberger et al. (2012); thus, state I was related to a daily $P_{\mathrm{p}}$ shape with peaking values at noon and minimum values recorded at night; state II was related to a half inverted curve with a sharp decrease of $P_{\mathrm{p}}$ at noon; and state III was related to a complete inversion of the $P_{\mathrm{p}}$ curve with minimum values recorded during the day and maximum values during the night. Figure 3 depicts the $\Psi_{\text {stem }}$ and $P_{\mathrm{p}}$ evolution of a representative L-WW and L-DS tree during the experiment as well as the classification of

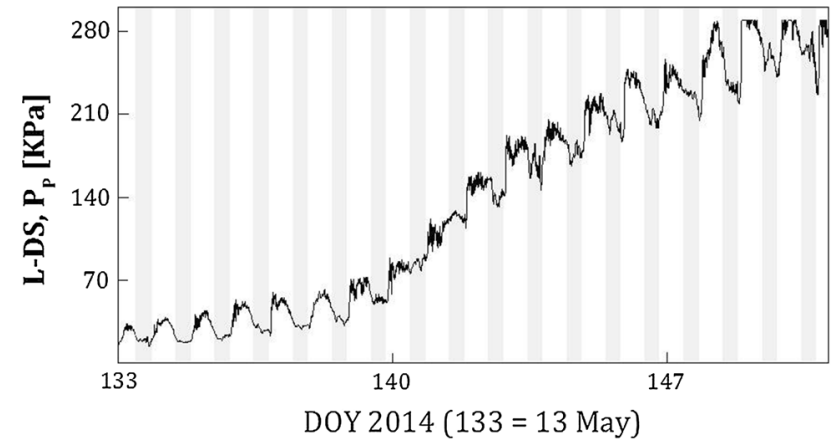

Fig. 2 Patch pressure $\left(P_{\mathrm{p}}\right)$ increase after clamping at the first stages of the leaf growth. Sensors were reclamped when $P_{\mathrm{p}}$ reached

the $P_{\mathrm{p}}$ shape curves in the above-mentioned states. The $P_{\mathrm{p}}$ curve in L-WW trees was all the time in state I, while L-DS trees showed a progressive change in the $P_{\mathrm{p}}$ curve shape from state I to state II and III as $\Psi_{\text {stem }}$ decreased during the drought cycles. Similarly, the $P_{\mathrm{p}}$ curve shape in L-DS trees changed from state III to state II and I when irrigation was resumed as $\Psi_{\text {stem }}$ recovered to similar values to the L-WW treatment. When data from all the Yara ZIM-probes of each treatment were analyzed, the $P_{\mathrm{p}}$ curve in L-WW trees was in the state I during the whole experiment. In L-DS trees, on the other hand, the $P_{\mathrm{p}}$ curve remained in the state I just $9.7 \%$ of the time while it was 34.7 and $55.6 \%$ of the time in the state II and III, respectively.

The assessment of the $P_{\mathrm{p}}$ curve shapes in both treatments during the experiment enabled the classification of each leaf turgor state within a range of $\Psi_{\text {stem. }}$. Statistically significant differences in mean $\Psi_{\text {stem }}$ were observed within trees from each leaf turgor state (Fig. 4). State I of leaf turgor was observed in trees with a $\Psi_{\text {stem }}$ higher than $-0.80 \mathrm{MPa}$. The intermediate state of leaf turgor (state II) was observed in trees with a $\Psi_{\text {stem }}$ compressed between -0.69 and $-1.33 \mathrm{MPa}$. Finally, the state III of leaf turgor was observed in trees with a $\Psi_{\text {stem }}$ ranging from -1.02 to $-2.40 \mathrm{MPa}$.

\section{Experiment 2: L-125-DS versus V-125-DS}

\section{Stem water potential and trunk diameter measurements}

Water restrictions applied in both treatments offered different results in terms of mean and maximum $\Psi_{\text {stem }}$ values. During the drought cycle, L-125-DS treatment registered an average $\Psi_{\text {stem }}$ of $-0.97 \pm 0.38 \mathrm{MPa}$ with a minimum value of $-1.80 \mathrm{MPa}$. In contrast, V-125-DS treatment had a higher mean $\Psi_{\text {stem }}$ value of $-0.80 \pm 0.16 \mathrm{MPa}$ and reached a minimum value of $-1.14 \mathrm{MPa}$. Significant differences were found in $\Psi_{\text {stem }}$ between trees grafted onto L and $\mathrm{V}$ rootstocks from 2 days of the beginning of the water restrictions (Fig. 5). 
Fig. 3 Stem water potential ( $\Psi_{\text {stem }}$, columns) and patch pressure $\left(P_{\mathrm{p}}\right.$, solid line $)$ evolution in one control (L-WW) and one non-irrigated (L-DS) tree during the two drought cycles. Different $P_{\mathrm{p}}$ curve shapes associated with different plant water status are also identified for each treatment (state I without lines; state II with low-density diagonal lines; and state III high-density diagonal lines). $\Psi_{\text {stem }}$ values are means; vertical lines indicate the standard errors, $n=4$. Shaded background columns indicate the nocturnal hours. The additional graph highlights the fast recovery of the plant water status when the drought period finishes. The $P_{\mathrm{p}}$ curve shows the evolution from the state III to state II in several hours

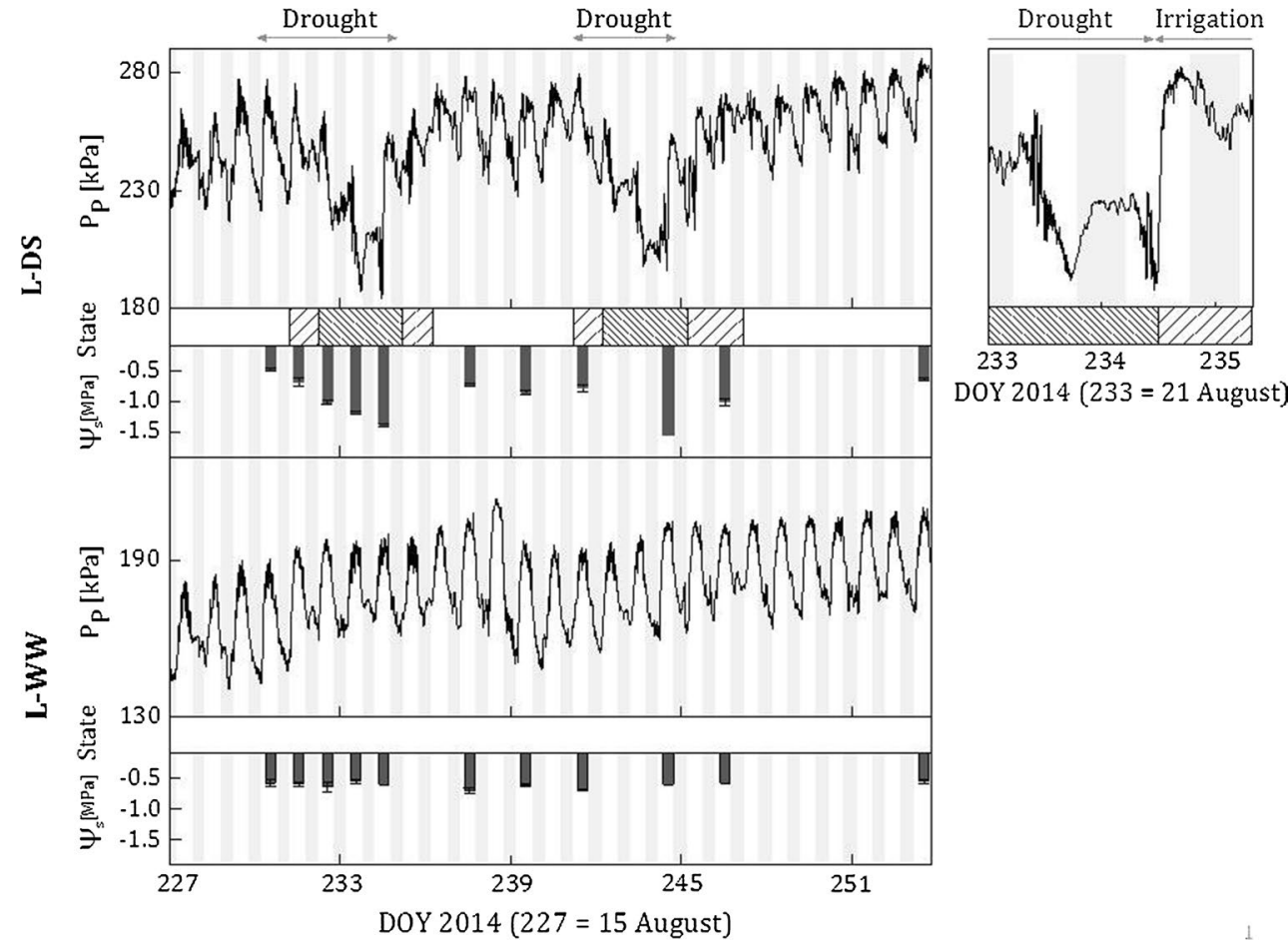

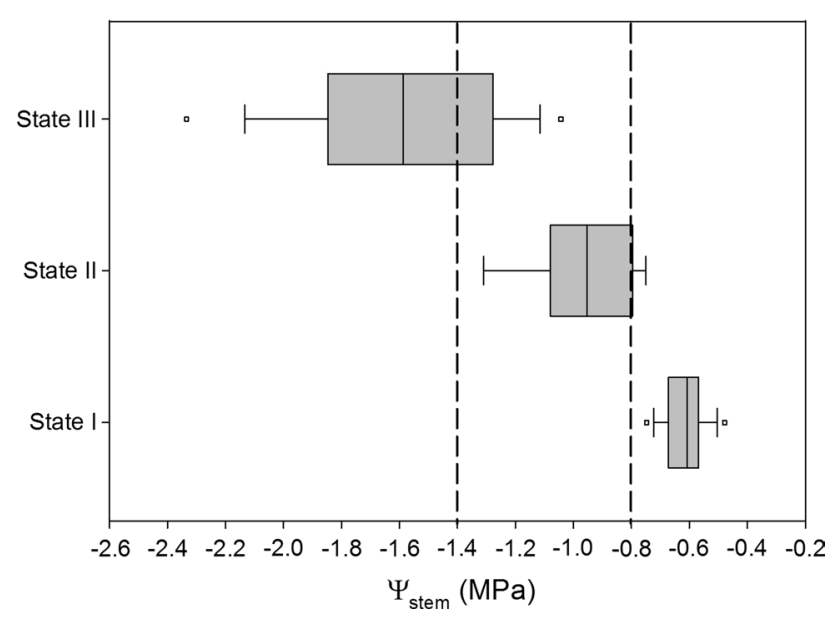

Fig. 4 Range of stem water potential $\left(\Psi_{\text {stem }}\right)$ values obtained during the two drought cycles within each leaf turgor. $\Psi_{\text {stem }}$ values are the average of five trees. Horizontal bars in boxes indicate the maximum and minimum values of $\Psi_{\text {stem }}$ for each state. Dotted border lines define $\Psi_{\text {stem }}$ thresholds for plant water status: adequate ( $\left.>-0.8 \mathrm{kPa}\right)$, mild to critical stress $(-0.8$ to $-1.4 \mathrm{kPa})$ and moderate stress $(<-1.4 \mathrm{kPa})$

Trunk diameter variations were monitored during the same period. MDS was lower in $\mathrm{V}(179.0 \pm 48.0 \mu \mathrm{m})$ than in $\mathrm{L}(215.4 \pm 67.8 \mu \mathrm{m})$ although no significant differences were observed between the rootstocks until the end of the drought cycle when $\Psi_{\text {stem }}$ reached values around $-1.6 \mathrm{MPa}$ in L trees (Fig. 5). The MXTD, on the other hand, was $42 \%$ higher in $\mathrm{V}$ than in $\mathrm{L}$ rootstocks (Fig. 6), and it is important to highlight that during the drought period, V maintained a constant growth rate slope in contrast to $\mathrm{L}$ where trunk growth rates decreased.

\section{Leaf turgor monitoring with the Yara ZIM-probes}

The evolution of the $P_{\mathrm{p}}$ curve shape in the different leaf turgor states (I, II and III) was linked to the $\Psi_{\text {stem }}$ measurements as did in experiment 1 (Fig. 7). The $P_{\mathrm{p}}$ curve in V-125-DS trees was most of the time in state I, while L-125-DS trees showed a gradual evolution from state I to state II and III. On average, L-125-DS was in state I, II and III 30, 30 and $60 \%$ of the time, respectively. However, V-125-DS was $80 \%$ of the time in state I and just $20 \%$ in state II and III. Each leaf turgor state within each rootstock corresponded to a range of $\Psi_{\text {stem }}$ (Fig. 8). L-125-DS reached lower values of $\Psi_{\text {stem }}(-1.03 \pm 0.18$ and $-1.41 \pm 0.23 \mathrm{MPa})$ than V-125-DS $(-0.91 \pm 0.10$ and $-1.02 \pm 0.29 \mathrm{MPa})$ for states II and III, respectively. However, state I in L-125-DS $(-0.66 \pm 0.10)$ was associated with higher $\Psi_{\text {stem }}$ values than in V-125-DS $(-0.74 \pm 0.12)$.

\section{Discussion}

The results presented in this work point out the Yara ZIMprobes as a reliable tool for continuously monitoring plant water status in Persimmon trees. Notwithstanding the $P_{\mathrm{p}}$ evolution observed just after clamping (April-May), in 

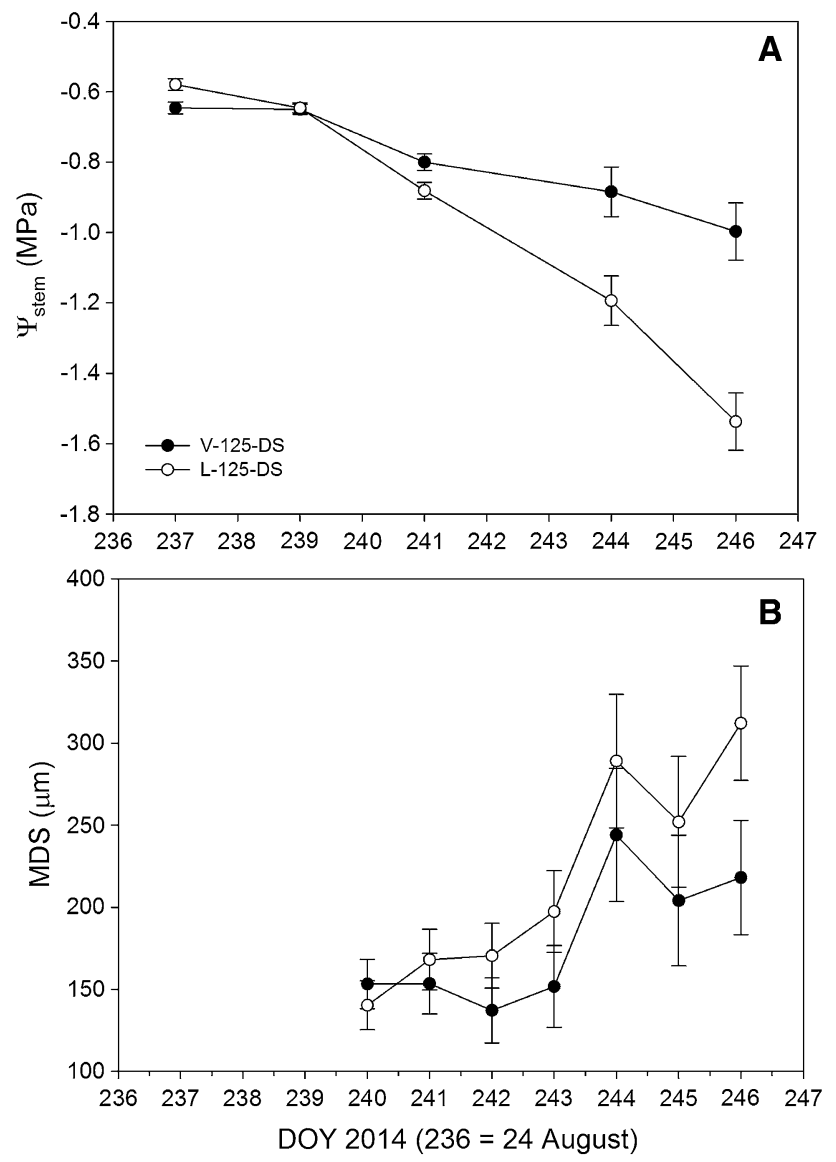

Fig. 5 Stem water potential $\left(\Psi_{\text {stem }}\right)$ and maximum daily trunk shrinkage (MDS) evolution in trees grafted onto lotus (L-125-DS) and virginiana (V-125-DS) during the drought cycle. Each point in figure (a, b) is the average of 10-20 leaves (5 trees per treatment) and 4 trees, respectively. Vertical bars represent the \pm LSD intervals

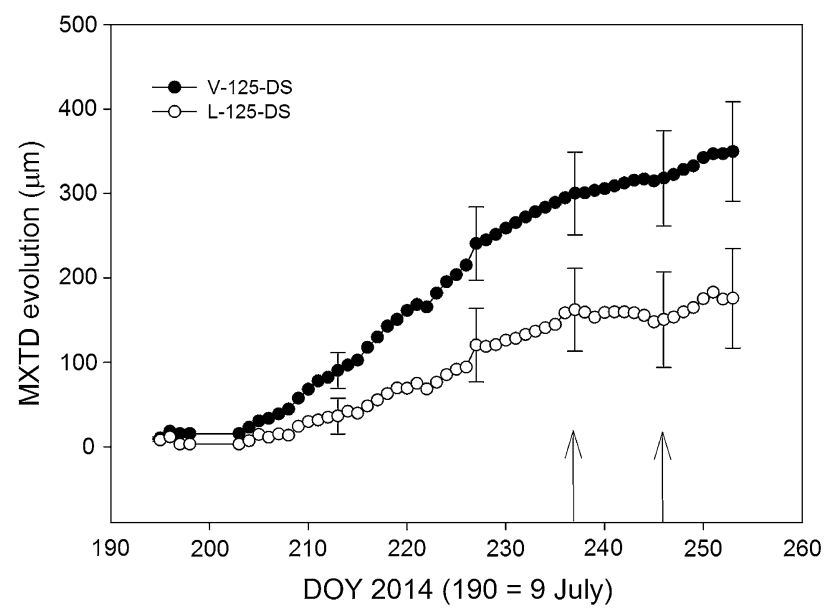

Fig. 6 Maximum daily trunk diameter (MXTD) monitored during the crop season. Each point is the average of four diameter trees. Vertical bars represent the \pm LSD intervals, and arrows indicate the starting of the drought cycles

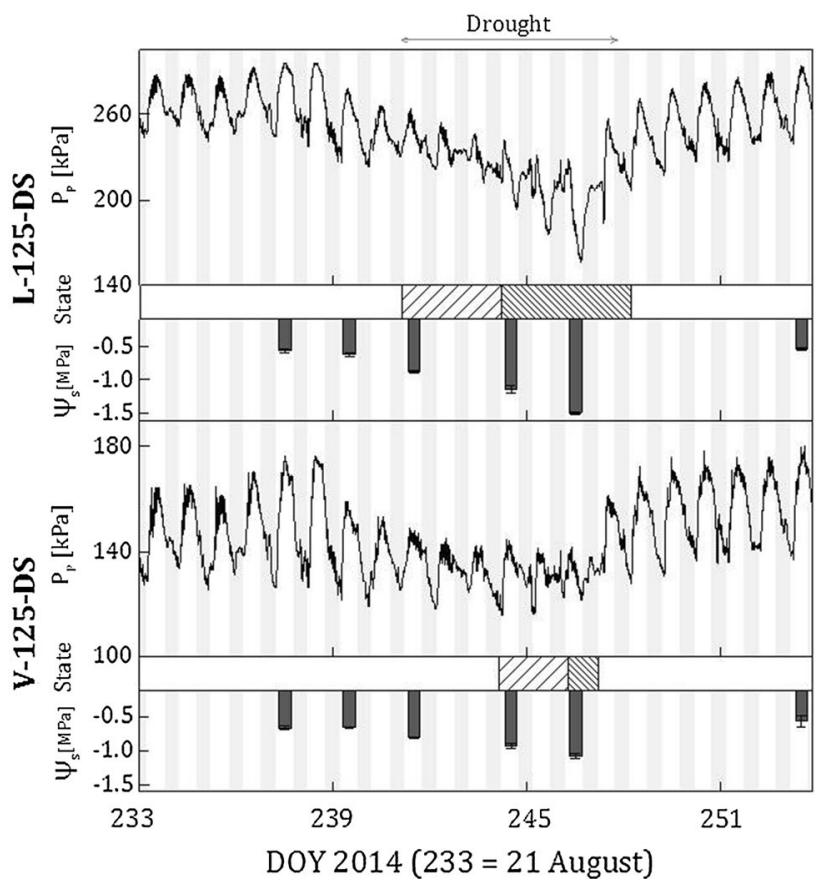

Fig. 7 Stem water potential ( $\Psi_{\text {stem }}$, columns $)$ and patch pressure $\left(P_{\mathrm{p}}\right.$, solid line) evolution in a plant grafted onto lotus (L-125-DS) and virginiana (V-125-DS) during the drought cycles applied. Different $P_{\mathrm{p}}$ curve shapes associated with different plant water status are also identified for each treatment (state I without lines; state II with low-density diagonal lines; and state III high-density diagonal lines). $\Psi_{\text {stem }}$ values are means; vertical lines indicate the standard errors, $n=4$. The shaded background columns indicate the nocturnal hours

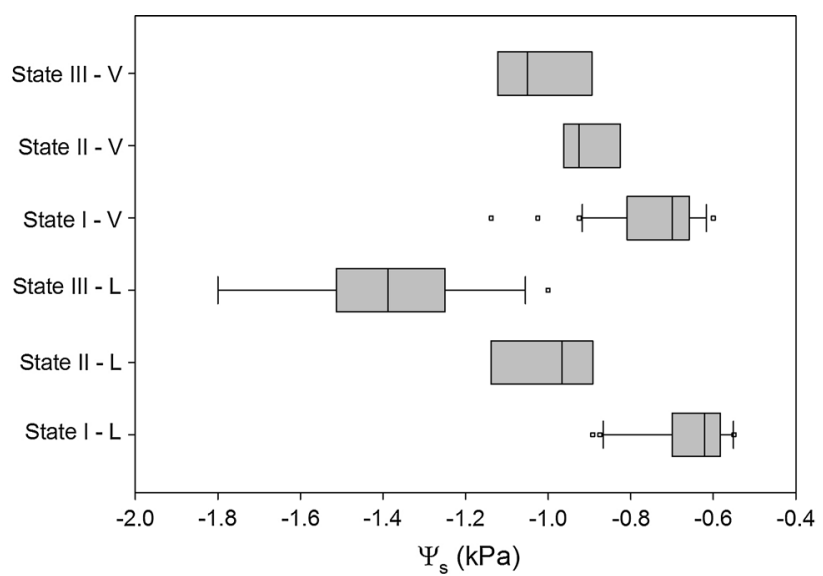

Fig. 8 Stem water potential $\left(\Psi_{\text {stem }}\right)$ values within each state of leaf turgor in trees grafted on lotus $(\mathrm{L})$ and virginiana $(\mathrm{V})$ trees. Horizontal bars indicate the maximum and minimum values of $\Psi_{\text {stem }}$ for each state

which daily and nightly $P_{\mathrm{p}}$ increased reaching the maximum pressure detected by the sensor in some of the probes (Fig. 2), leaf turgor monitoring with the Yara ZIM-probes enabled the detection of mild to severe water stress in 
Table 1 Stem water potential $\left(\Psi_{\text {stem }}\right)$ associated with each of the leaf turgor states observed in control (L-WW) and non-irrigated (L-DS) trees. Water status for the average, maximum and minimum $\Psi_{\text {stem }}$ recorded within each state is also shown

\begin{tabular}{llllllll}
\hline State & $\Psi_{\mathrm{s}}(\mathrm{MPa})$ & & & & Water status \\
\cline { 2 - 3 } & Average & Maximum & Minimum & & Average & Maximum & Minimum \\
\hline I & $-0.61 \pm 0.08$ & -0.79 & -0.47 & & Adequate & Adequate & Adequate \\
II & $-0.98 \pm 0.19$ & -1.33 & -0.69 & & Mild stress & Moderate stress & Adequate \\
III & $-1.58 \pm 0.36$ & -2.40 & -1.02 & & Moderate stress & Severe stress & Mild stress \\
\hline
\end{tabular}

The interpretation of the $\Psi_{\text {stem }}$ values in relation to the degree of water stress is derived from previous experiments carried out in order to determine Persimmon trees responses to different irrigation regimes (Badal et al. 2010, 2013; Buesa et al. 2013)
L-DS, L-125-DS and V-125-DS trees as well as their recovery when irrigation was resumed.

The particular $P_{\mathrm{p}}$ evolution observed just after clamping in Persimmon trees has not been reported for other fruit tree crops. This effect could be related to the structure of Persimmon leaves which is more complex than in other crops due to their density and thickness. Moreover, the foliar limb is slightly wavy and the main and secondary nervation stands out on the abaxial surface (Giordani et al. 2015), which most likely hamper the proper continuity between magnets. More studies would be needed regarding this matter to untangle this unusual behavior of $P_{\mathrm{p}}$ and be able to monitor leaf turgor during the whole growing period of Persimmon trees.

Different approaches can be followed to detect plant water stress when analyzing data from the Yara ZIM-probes (Zimmermann et al. 2013b). The assessment of the maximum daily $P_{\mathrm{p}}$ seems to be a useful method for clementine trees, in which a half or complete inversion of the $P_{\mathrm{p}}$ curve does not often occur even under severe $\left(\Psi_{\text {stem }}\right.$ of up to $-1.9 \mathrm{MPa}$ ) water-stressed conditions (Ballester et al. 2016). Contrary to this and more in the line of what has been reported for other crops like almond, eucalyptus, avocado (Zimmermann et al. 2013b) and olive trees (Fernández et al. 2011; Ehrenberger et al. 2012; Padilla-Díaz et al. 2015), the change observed in the $P_{\mathrm{p}}$ curve profile was shown as a useful method to detect drought stress in Persimmon trees. The change in the $P_{\mathrm{p}}$ curve profile from a normal curve peaking at midday to a half and eventually complete inversion of the curve as a consequence of the water replacement for air into the parenchyma tissue of cells leaves [see Ehrenberger et al. (2012) for more details] made possible to differentiate between three ranges of $\Psi_{\text {stem }}$ linked to well-watered, moderate and severe water-stressed trees. The $P_{\mathrm{p}}$ curve profiles were classified in three states of leaf turgor as described in Ehrenberger et al. (2012). Thus, each state was linked to a range of $\Psi_{\text {stem }}$ and consequently to a plant water status (Table 1). State I, in which L-WW trees remained during the whole study and L-DS trees just less than $10 \%$ of the time during the drought cycles, was linked to $\Psi_{\text {stem }}$ values above $-0.8 \mathrm{MPa}$, considered of well-watered Persimmon trees (Badal et al. 2010). The
$\Psi_{\text {stem }}$ thresholds for the intermediate state of leaf turgor $(-0.69$ and $-1.33 \mathrm{MPa})$ were overlapped with the upper limit of state I $(-0.79 \mathrm{MPa})$ and the lower limit of state III $(-1.02 \mathrm{MPa})$ (Table 1). State II would include then trees with mild to moderate water stress (George et al. 1995), whereas trees within the state III, with $\Psi_{\text {stem }}$ values ranging from -1.02 to $-2.40 \mathrm{MPa}$, would indicate trees with moderate to severe water stress. Additionally, irrigation effect and water status recovery were also detected by the Yara ZIM-probes immediately. When irrigation was resumed after a drought cycle, the daily $P_{\mathrm{p}}$ curves evolved from the inverse shape to the half inverse or even the normal shape directly (see this behavior highlighted in Fig. 3).

These results show that leaf turgor monitoring with the Yara ZIM-probes could possibly be used in Persimmon trees for irrigation scheduling. Irrigation management has been proven as a useful tool to reduce fruit drop in Persimmon trees cv. 'Rojo Brillante' (Badal et al. 2013). Water restrictions applied during spring or summer have been reported as effective strategies to decrease fruit drop and significantly increase water use efficiency in this crop (Buesa et al. 2013). Nevertheless, fruit growth in this particular cv. ('Rojo Brillante') is highly sensitive to deficit irrigation and a proper management of the water stress reached by the trees is crucial to do not impair fruit size and reduce farm profitability (Buesa et al. 2013). The use of the Yara ZIM-probes in orchards under deficit irrigation strategies could provide continuous information of plant water status for an adequate management of water stress. Based on Buesa et al. (2013), fruit drop could be reduced by maintaining trees within the state II of leaf turgor during either spring or summer for a couple of weeks and then leading them to state I by increasing water allocations. The unusual $P_{\mathrm{p}}$ readings observed after clamping should not be a problem when using the probes in RDI orchards provided that these were installed in the trees with enough time to stabilize before the period of water restrictions, which in spring RDI strategies is recommended from late May to mid-July. Further research on how crop load and other factors apart from water status influence leaf turgor would be valuable in order to design deficit irrigation strategies based on Yara ZIM-probe readings. 
Compared with the results obtained by Fernández et al. (2011) in a similar study conducted in Seville on olive trees, states I, II and III of leaf turgor in Persimmon trees were related to higher values of $\Psi_{\text {stem }}$. These results could be expected since olive is a well-adapted crop to waterlimited environments (Connor 2005), while Persimmon has been reported as a crop not highly sensitive to vapor pressure deficit and with poor stomatal regulation (Badal et al. 2010; Ballester et al. 2013b).

In this study, the sensitivity of the Yara ZIM-probe to detect drought stress was tested in the experiment 2 comparing trees grafted on contrasting rootstocks to drought tolerance. $\mathrm{V}$ rootstock is known to produce more vigorous plants (larger root system) than L, which ensure a better performance of trees when are planted in heavy and dry soils (Badenes et al. 2015). Both rootstocks are used in the area of study although $90 \%$ of the production stands on trees grafted onto L. Results obtained from the $\Psi_{\text {stem }}$ and trunk diameter variation measurements showed that trees grafted onto $\mathrm{V}$ remained in a better plant water status than those grafted onto $\mathrm{L}$ during the drought cycle. These differences in water status were also reflected in the leaf turgor measurements since trees grafted onto $\mathrm{V}$ remained more days in state I (well-watered conditions, 8 out of 10 days) than those grafted onto L ( 3 out of 10 days). The use of the Yara ZIM-probes to monitor leaf turgor in combination with other plant physiological assessments may provide then useful information to assess the response of rootstocks to drought stress in order to identify those more adequate for a range of scenarios with different water-limiting conditions.

\section{Conclusions}

The results obtained from this study show that continuous leaf turgor monitoring with the Yara ZIM-probes enabled the detection of water stress in Persimmon trees. Three states of leaf turgor were identified depending on the shape of the $P_{\mathrm{p}}$ curve (normal, half inverted and total inverted) obtained from the probes. State I ( $\Psi_{\text {stem }}$ above $\left.-0.8 \mathrm{MPa}\right)$ was observed during the whole experiment in the wellwatered trees and when water restrictions were not applied in the drought-stressed treatments. States II and III of leaf turgor were observed just during the drought cycles when trees reached $\Psi_{\text {stem }}$ values considered of mild to severe water stress.

These results suggest, on one hand, that the Yara ZIMprobe could be a possible tool to be used in this crop for scheduling irrigation. Further research, however, is needed to address different aspects such as the unusual $P_{\mathrm{p}}$ evolution observed just after clamping or how $P_{\mathrm{p}}$ is influenced by the seasonal variability in tissue water relations, or crop load before attempting to recommend its use for irrigation scheduling purposes. Its use along with other physiological measurements, on the other hand, may be used to assess the tolerance of rootstocks to drought stress with the aim to identify those more adequate for semiarid environments.

Acknowledgments The authors thank J. Castel, E. Badal and T. Yeves for their help with the installation and maintenance of the Yara ZIM-probe equipment. This experiment has been funded by the European Project WEAM4i (Water and Energy Advanced Management for Irrigation), grant agreement 619061 and FEDER-MINECO EASYRIEGO (IPT-2012-0950-310000). M. A. Martínez-Gimeno acknowledges the financial support received from the Spanish Ministry of Education, Culture and Sports (MECD) program Formación Profesoreado Univeritario (FPU).

Open Access This article is distributed under the terms of the Creative Commons Attribution 4.0 International License (http://creativecommons.org/licenses/by/4.0/), which permits unrestricted use, distribution, and reproduction in any medium, provided you give appropriate credit to the original author(s) and the source, provide a link to the Creative Commons license, and indicate if changes were made.

\section{References}

Allen RG, Pereira RS, Raes D, Smith M (1998) Crop evapotranspiration-guidelines for computing crop water requirements. Irrigation and drainage 56. FAO, Rome, p 56

Arnal L, Río MA (2003) Removing astringency by carbon dioxide and nitrogen-enriched atmospheres in Persimmon fruit cv. "Rojo Brillante". J Food Sci 68(4):1516-1518

Badal E, Buesa I, Guerra D, Bonet L, Ferrer P, Intrigliolo DS (2010) Maximum diurnal trunk shrinkage is a sensitive indicator of plant water, stress in Diospyros kaki (Persimmon) trees. Agric Water Manag 98(1):143-147

Badal E, El-Mageed TA, Buesa I, Guerra D, Bonet L, Intrigliolo DS (2013) Moderate plant water stress reduces fruit drop of "Rojo Brillante" persimmon (Diospyros kaki) in a Mediterranean climate. Agric Water Manag 119:154-160

Badenes ML, Naval MM, Martínez-Calvo J, Giordani E (2015) Material vegetal y mejora genética. In: Badenes ML, Intrigliolo DS, Salvador A, Vicent A (eds) El cultivo del caqui. Generalitat Valenciana, Valencia, pp 17-33

Ballester C, Castel J, Jimenez-Bello MA, Castel JR, Intrigliolo DS (2013a) Thermographic measurement of canopy temperature is a useful tool for predicting water deficit effects on fruit weight in citrus trees. Agric Water Manag 122:1-6

Ballester C, Jimenez-Bello MA, Castel JR, Intrigliolo DS (2013b) Usefulness of thermography for water stress detection in citrus and persimmon trees. Agric For Meteorol 168:120-129

Ballester C, Castiella M, Zimmermann U, Rüger S, Martínez-Gimeno MA, Intrigliolo DS (2016) Usefulness of the Yara ZIM plant technology for detecting plant water stress in Clementine and Persimmon trees. Acta Hortic (in press)

Buesa I, Badal E, Guerra D, Ballester C, Bonet L, Intrigliolo DS (2013) Regulated deficit irrigation in persimmon trees (Diospyros kaki) cv. 'Rojo Brillante'. Sci Hortic 159:134-142

Connor DJ (2005) Adaptation of olive (Olea europaea L.) to water-limited environments. Crop and pasture. Science 56(11):1181-1189 
Ehrenberger W, Rüger S, Rodríguez-Domínguez CM, Díaz-Espejo A, Fernández JE, Moreno J, Zimmermann D, Sukhorukov VL, Zimmermann U (2012) Leaf patch clamp pressure probe measurements on olive leaves in a nearly turgorless state. Plant Biol 4(4):666-674

Fernández JE (2014) Plant-based sensing to monitor water stress: applicability to commercial orchards. Agric Water Manag 142:99-109

Fernández JE, Cuevas MV (2010) Irrigation scheduling from stem diameter variations: a review. Agric For Meteorol 150(2):135-151

Fernández JE, Rodríguez-Domínguez CM, Pérez-Martín A, Zimmermann U, Rüger S, Martín-Palomo MJ, Torres-Ruíz JM, Cuevas MV, Sann C, Ehrenberger W, Díaz-Espejo A (2011) Online-monitoring of tree water stress in a hedgerow olive orchard using the leaf patch clamp pressure probe. Agric Water Manag 100:25-35

George AP, Nissen RJ, de Kruiff HCB (1995) Effects of plant water stress on fruit set of non-astringent persimmon under controlledenvironment conditions. Acta Hortic 409:117-121

Giordani E, Picardi E, Radice S (2015) Mofología y fisiología. In: Badenes ML, Intrigliolo DS, Salvador A, Vicent A (eds) El cultivo del caqui. Generalitat Valenciana, Valencia, pp 17-33

Intergovernmental Panel on Climate Change, IPCC (2014) Climate change 2014-impacts, adaptation and vulnerability: regional aspects. Cambridge University Press, Cambridge

Jones HG, Serraj R, Loveys BR, Xiong L, Wheaton A, Price AH (2009) Thermal infrared imaging of crop canopies for the remote diagnosis and quantification of plant responses to water stress in the field. Funct Plant Biol 36(11):978-989

Kant S, Burch D, Ehrenberger W, Bitter R, Rüger S, Mason J, Rodin J, Materne M, Zimmermann U, Spangenberg G (2014) A novel crop water analysis system: identification of water stress tolerant genotypes of canola (Brassica napus L.) using non-invasive magnetic turgor pressure probes. Plant Breed 133(5):602-608

Ortuño MF, Conejero W, Moreno F, Moriana A, Intrigliolo DS, Biel C, Mellisho CD, Pérez-Pastor A, Domingo R, Ruiz-Sánchez MC, Casadesus J, Bonany J (2010) Could trunk diameter sensors be used in woody crops for irrigation scheduling? A review of current knowledge and future perspectives. Agric Water Manag 97(1):1-11

Padilla-Díaz CM, Rodriguez-Dominguez CM, Hernandez-Santana V, Perez-Martin A, Fernández JE (2015) Scheduling regulated deficit irrigation in a hedgerow olive orchard from leaf turgor pressure related measurements. Agric Water Manag. doi:10.1016/j. agwat.2015.08.002

Perucho R (2015) El cultivo del caqui. antecedentes e importancia económica. In: Badenes ML, Intrigliolo DS, Salvador A, Vicent AEd (eds) El cultivo del caqui. Generalitat Valenciana, Valencia, pp 17-33

Rodriguez-Dominguez CM, Ehrenberger W, Sann C, Rüger S, Sukhorukov VL, Martín-Palomo MJ, Diaz-Espejo A, Cuevas MV,
Torres-Ruiz JM, Perez-Martin A, Zimmermann U, Fernández JE (2012) Concomitant measurements of stem sap flow and leaf turgor pressure in olive trees using the leaf patch clamp pressure probe. Agric Water Manag 114:50-58

Rüger S, Netzer Y, Westhoff M, Zimmermann D, Reuss R, Ovadiya S, Gessner P, Zimmermman D, Schwartz A, Zimmermann U (2010) Remote monitoring of leaf turgor pressure of grapevines subjected to different irrigation treatments using the leaf patch clamp pressure probe. Aust J Grape Wine Res 16(3):405-412

Rüger S, Ehrenberger W, Zimmermann U, Ben-Gal A, Agam N, Kool D (2011) The leaf patch clamp pressure probe: a new tool for irrigation scheduling and deeper insight into olive drought stress physiology. Acta Hortic 888:223

Ruiz-Sanchez MC, Domingo R, Castel JR (2010) Review. Deficit irrigation in fruit trees and vines in Spain. Span J Agric Res $8(2): 5-20$

Turner NC (1981) Techniques and experimental approaches for the measurement of plant water status. Plant Soil 58:339-366

Westhoff M, Schneider H, Zimmermann D, Mimietz S, Stinzing A, Wegner LH, Kaiser W, Krohne G, Shirley S, Jakob P, Bamberg E, Bentrup F-W, Zimmermann U (2008) The mechanisms of refilling of xylem conduits and bleeding of tall birch during spring. Plant Biol 10:604-623

Westhoff M, Reuss R, Zimmermann D, Netzer Y, Gessner A, Geßner P, Zimmermann G, Wegner LH, Bamberg E, Schwartz A, Zimmermann U (2009) A non-invasive probe for online-monitoring of turgor pressure changes under field conditions. Plant Biol 11:701-712

Zimmermann D, Reuss R, Westhoff M, Gessner P, Bauer W, Bamberg E, Bentrup F-W, Zimmermann U (2008) A novel, non-invasive, online-monitoring, versatile and easy plant based probe for measuring leaf water status. J Exp Bot 59:3157-3167

Zimmermann U, Bitter R, Schüttler A, Ehrenberger W, Rüger S, Bramley H, Siddique K, Arend M, Bader MKF (2013a) Advanced plant-based, internet-sensor technology gives new insights into hydraulic plant functioning. Acta Hortic. In: IX international workshop on sap flow by ISHS, vol 991, pp $313-320$

Zimmermann U, Bitter R, Marchiori PER, Rüger S, Ehrenberger W, Sukhorukov VL, Schüttler A, Ribeiro RF (2013b) A non-invasive plant-based probe for continuous monitoring of water stress in real time: a new tool for irrigation scheduling and deeper insight into drought and salinity stress physiology. Theor Exp Plant Physiol 25:3-12

Zimmermman U, Israeli Y, Zhou A, Schwartz A, Bamberg E, Zimmermann D (2009) Effects of environmental parameters and irrigation on the turgor pressure of banana plants measured using the non-invasive, online monitoring leaf patch clamp pressure probe. Plant Biol 12(3):424-436 